\title{
The Dependence of the Efficiency of the Condensing Boiler by use and Climatic zone
}

\author{
Pavel Aleksandrovich Khavanov and Anatoly Sergeevich Chulenyov
}

Moscow State University of Civil Engineering, Russia, 129337, Moscow, Yaroslavskaya Road, 26.

DOI: http://dx.doi.org/10.13005/bbra/1985

(Received: 27 September 2015; accepted: 05 November 2015)

\begin{abstract}
We considered and analyzed heat engineering parameters of condensing boilers in the autonomous heating systems. The technique of tests of condensation boilers is developed. Presented resulting cumulative process, cooling and drying the flue gas condensing boilers in the id of the combustion products chart. We considered and analyzed the test results of wall gas condensing boilers Baxi Duo Tec Compact and De Dietrich Innovers PRO MCA 45 under different operating conditions. We were analyzed according to the temperature and enthalpy of the flue gas heat loss from the physical warmth of the flue gas, the efficiency of the boiler temperature of the coolant. Shows the change of heat losses from exhaust gases and in the actual full cooling of the flue gases, and the difference between the values of the moisture content of the flue gases at various temperatures of the coolant at the boiler inlet temperature and the dew point. The obtained relationships shown in the graphs, draw conclusions about the performance of the condensing heat generator for various operating modes. Presented and analyzed the results of the evaluation time of the boilers in condensing mode by constructing graphs of temperature for some cities in Russia in various climatic zones. Shows selected climate indices that characterize the probable duration of the heat sources in the condensing mode, and are a necessary material for their account in the analysis of the value of the efficiency of the boiler in the annual cycle of his work. Analyzed according to duration of the boiler condensing mode of the estimated ambient temperature and boiler efficiency of the coolant temperature at the inlet to the heat exchanger of the boiler. Based on climatic data, conclusions were drawn about the value of the efficiency of the gas condensing boiler.
\end{abstract}

Key words: Condensing boiler, heat-engineering parameters, heat, flue gas, heat losses, efficiency.

Modern trends in the implementation of energy-saving solutions in the system boiler and heat the buildings for heating, ventilation and hot water in most cases, lead to the use of non-energyefficient solutions, in particular, in some cases using heat pumps, solar power plants, wind power plants, in plants using biological resources and combination devices.

Justification of energy efficiency of their application demands consideration in each case of the accounting of all efficiency, operational and

* To whom all correspondence should be addressed. economic factors (Kalchevsky, 2012).

At the same time, practically in all cases of use of the condensation heat generating equipment provides energy efficiency of a technical solution at the expense of a fuel component in operational costs, despite growth of capital investments in installations. It is confirmed by adoption by the European Union countries of the decision on transition on objects of new construction in inhabited sector from the third quarter 2015 only on condensation heat generators.

Recently gas boilers occupy a significant segment of the heating equipment (Khavanov, 2014). They are easy to use, have a number of advantages over conventional heat generators of low power applicable to the autonomous heating. 
However, all the advantages of heat engineering these boilers are based on high efficiency. Many publications states that the efficiency of condensing boilers is greater than $100 \%$, which is obviously not correct and should be seen as a publicity stunt.

\section{METHOD}

Determination of heat loss from the exhaust gases

In general, the efficiency of condensing heat generator (gross) can be identified by forward and reverse heat balance using the higher heating value of fuel $Q_{H}^{V}$. In the first case, the efficiency of the heat generating unit is given direct calculation largest usable heat in the form (Bruykhanov \& Shevchenko, 2014):

$\eta=\frac{Q_{1}}{B \cdot Q_{H}^{V}}$,

$Q_{1}$ - useful (heat) power, $\mathrm{kW}$;

$Q_{H}^{V}$ - higher heating value, $\mathrm{kJ} / \mathrm{kg}, \mathrm{kJ} / \mathrm{m}^{3}$;

$B$-fuel consumption, $\mathrm{kg} / \mathrm{s}, \mathrm{m}^{3} / \mathrm{s}$.

Components of heat losses by direct balance heat generating unit is defined as the sum of all heat losses, without going into detail, since in practice quite often this is not required in accordance with the purpose of determining the efficiency of the heat generator only.

Detailed analyze heat engineering performance and efficiency of the heat generating unit can be the reverse heat balance by calculating the components of the heat losses after summation of their values, the determination of the useful (power) heat:

$Q_{1}=B \cdot Q_{H}^{V}-\left(Q_{2}+Q_{3}+Q_{4}+Q_{5}+Q_{6}\right)$,

$Q_{2}$ - the loss of heat from the exhaust gases, KW, MW;

$Q_{3}$ - the loss of heat from the incomplete burning of chemical, kW, MW;

$Q_{4}$ - the loss of heat from mechanical incomplete combustion of fuel, kW, MW;

$Q_{5}$ - the loss of heat from the external cooling, $\mathrm{kW}$, MW;

$Q_{6}$ - the loss of heat from the slag, $\mathrm{kW}, \mathrm{MW}$.

Generally during the work of the heat generating installation on gaseous fuel in components of thermal losses there are no losses with mechanical incompleteness of burning and with physical heat of slags.

$\eta=\frac{B \cdot Q_{H}^{V}-\left(Q_{2}+Q_{3}+Q_{5}\right)}{B \cdot Q_{H}^{V}}=1-\left(q_{2}+q_{3}+q_{5}\right)$,

$q_{2} ; q_{3} ; q_{5}$ - heat loss (in shares), related to $1 \mathrm{~m}^{3}$ burnt gaseous fuels.

Combining technical capabilities, practical difficulties, complete analysis of the heat source for the forward and reverse balance, particularly for installations of condensation type, it should be noted that the expected accuracy of the required quantity efficiency condensing heat source depends on the accuracy and the required number of measurements, the number of measured values and error data used (Lukankin et al., 2006). Estimating the expected total value of the mean square error in determining the efficiency of the heat source:

By direct balance

$\Delta \delta \%=\sqrt{\sum_{i=1}^{5} \Delta \delta_{i}^{2}}=\sqrt{2,25+0,25+0,01+0,01+4}=\sqrt{6,52}=2,55 \%$

$\Delta \delta_{\Sigma}= \pm 2,55 \%$

By reverse balance

$\Delta \delta \%=\sqrt{\sum_{i=1}^{9} \Delta \delta_{i}^{2}}=\sqrt{4+4+4+0,25+0,01+2,25+0,01+0,01+0,01}=\sqrt{14,5}=3,81 \%$ $\Delta \delta_{\Sigma}= \pm 3,81 \% \approx 4 \%$

Thus, first of all because of smaller number of measurements, on direct balance the defined error is less, than on the reverse. In the analysis of operation of condensation heat generators, drawing up thermal balances is made on the highest warmth of combustion of fuel $Q_{H}^{V}$ :

$Q_{H}^{V}=Q_{L}^{V}+24,62 \cdot\left(8,94 H^{r}+W^{r}\right)$

$Q_{L}^{V}$ - lower heating value, $\mathrm{kJ} / \mathrm{kg}, \mathrm{kJ} / \mathrm{m}^{3}$;

$H^{r} ; W^{r}$ - the content of hydrogen and moisture in the working mass of fuel, $\%$.

Identify the degree of utilization of the heat of condensation of water vapor from the volume of the combustion products can only be analyzing losses from exhaust gases, i.e., reverse thermal balance (Isachenko et al., 1975).:

$Q_{\mathrm{H}_{2} \mathrm{O}}=24,62 \cdot\left(8,94 H^{r}+W^{r}\right)$

It should also be borne in mind that in 
modern condensing heat generators of heat loss from the exhaust gases are the greatest part of the heat loss is often an order of magnitude greater than losses $Q_{3}$ and $Q_{5}$.

Losses chemical incomplete combustion gas determined according to the analysis of the combustion products at the output of the condensing heat source:

$Q_{3}=B \cdot V_{f g}^{\prime \prime} \cdot\left(126,6 C O+108,1 H_{2}+358,3 C_{4}\right), \mathrm{kW}$

$V_{f g}^{\prime \prime}$ - the total volume of flue gas at the outlet of the heat source, $\mathrm{m}^{3} / \mathrm{m}^{3} ; \mathrm{m}^{3} / \mathrm{kg}$;

$\mathrm{CO} ; \mathrm{H}_{2} ; \mathrm{CH}_{4}$ - content in the combustion products of carbon monoxide, hydrogen and methane, $\%$.

Focusing on the modern requirements to the burners in the condensing heat generators of low power and are used in most cases supercharged burner complete premix, the percentage content of products is not complete combustion of $\mathrm{CO} \% \mathrm{H} 2 \%$; $\mathrm{CH} 4 \%$ corresponds to a very "hard” rules of carbon oxide (up to 2000ppm) (Petukhov \& Shickov, 1987).

In this case, we can talk about the values

$q_{3}=\frac{Q_{3}}{B \cdot Q_{H}^{V}}$ that determine the limits of error

(4\%) will be:

$q_{3}=0,25 \pm 0,01 \%$

The value of the loss of heat from the external cooling $Q_{5}$ is calculated as the total external surface of the heat heat source:

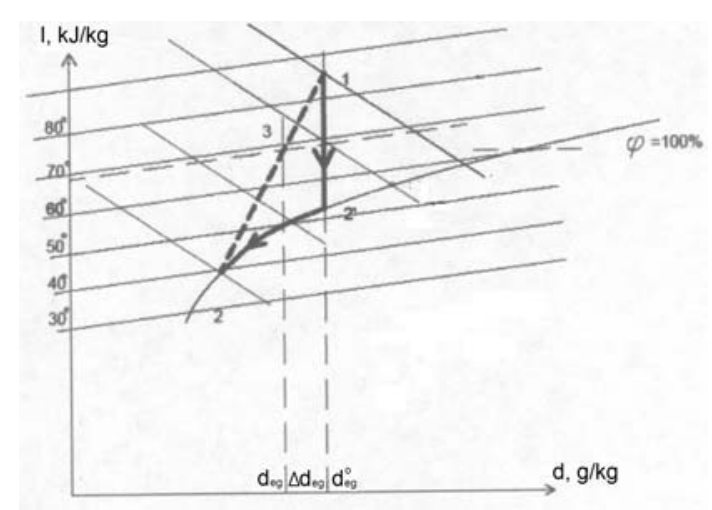

Fig. 1. The processes of cooling of the combustion products in the condensing boiler
$Q_{5}=\sum_{j=1}^{n} a_{j} f_{j}\left(t_{j}-t_{\text {int }}\right), \mathrm{kW}$

$j$ - heat generator surface element;

- heat generator surface; $\mathrm{m}^{3}$;

$a$ - heat transfer coefficient $\mathrm{W} / \mathrm{m}^{2} \cdot \mathrm{K}$;

- temperature of the surface $\mathrm{j}^{0} \tilde{\mathrm{N}}, \mathrm{K}$;

$t_{\text {int }}$ - temperature of internal air ${ }^{0} \tilde{\mathrm{N}}, \mathrm{K}$.

Condensing boilers all manufacturers constructively carried out with low-temperature external surfaces and effective heat insulation, so

the value of: $q_{5}=\frac{Q_{5}}{B \cdot Q_{H}^{V}}$ rarely exceeds $1.25-1.5 \%$, which is a fairly high degree of validity allows to take into account, for the "typical" structures condensing boilers value $q_{5}=1,25 \pm 0,25 \%$. The greatest difficulties in the analysis of the heat balance of the condensation heat generator is a reliable estimate of the loss of heat from the exhaust gases and in particular to that part of the heat $Q_{2}$, which corresponds to the heat is not condensed from the flue gas water vapor (or vice versa is not condensed), i.e., of the total amount per $1 \mathrm{~m}^{3}$ of gas content (Trembovlya, 1977):

$$
M_{\mathrm{H}_{2} \mathrm{O}}=0,01 \cdot\left(8,94 H^{r}+W^{r}\right), \mathrm{kg} / \mathrm{m}^{3} \text { dry gas. }
$$

The main difficulty lies in the accurate assessment of the products of combustion of residual partial pressure of water vapor, or a number (which is equivalent to the value of the moisture content of the flue gas flue $\mathrm{d}, \mathrm{g} / \mathrm{kg}$ ) even at a known temperature flue gas.

\section{Cooling process}

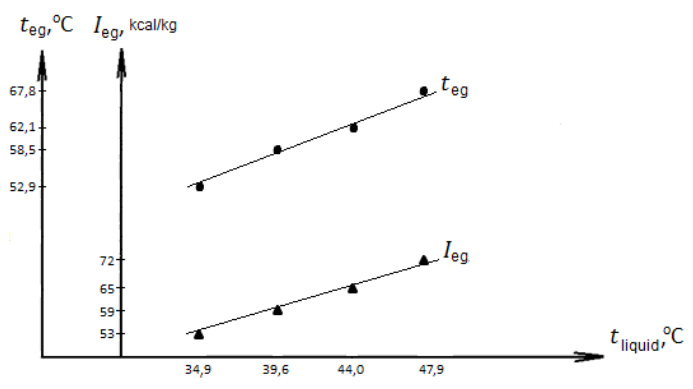

Fig. 2. Dependence of $t_{e g}$ and $I_{e g}$ from water temperature on an entrance to a boiler 
Condensing boilers tests show that the actual exhaust gas temperature above the dew point for the initial composition of the combustion products at the same time holds the condensation of water vapor in the heating surface.

It is explained by mixture behind convective surfaces of the heat generator (an exit) some part of deeply cooled "drained" products of combustion and some part of "transit" combustion gases (Roddatis \& Poltaretsky, 1989). Total process (1-2-3) can be represented in the id - diagram of the combustion products (Aronov, 1964) from the final state at point 3 (figure 1), assuming that the processes we apply the principle of additive (Miram \& Pavlenko, 2011).

Realistically determine the composition of the flue gas can be reliably determined, the experiment flow of condensate from the boiler:

$$
\begin{aligned}
& B \cdot \tau \cdot M_{\mathrm{H}_{2} \mathrm{O}}^{e g}=M_{\mathrm{H}_{2} \mathrm{O}}^{o} \cdot B \cdot \tau-G_{\text {con }}, \text { or } \\
& M_{\mathrm{H}_{2} \mathrm{O}}^{e g}=M_{\mathrm{H}_{2} \mathrm{O}}^{o}-\frac{G_{c o n}}{B \cdot \tau}, \mathrm{kg} / \mathrm{m}^{3}
\end{aligned}
$$

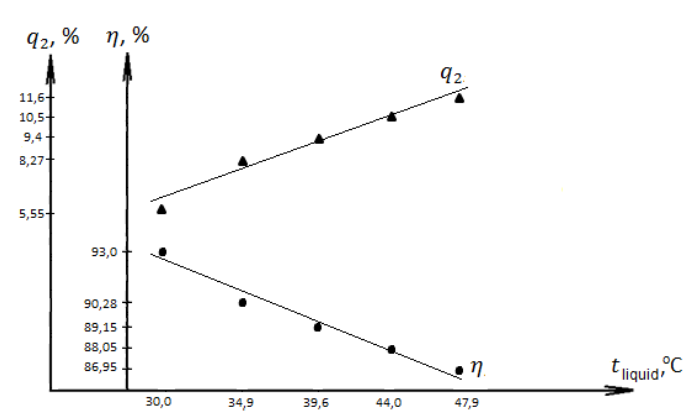

Fig. 3. Dependence of $q_{2}$, and the efficiency from water temperature on an entrance to a boiler

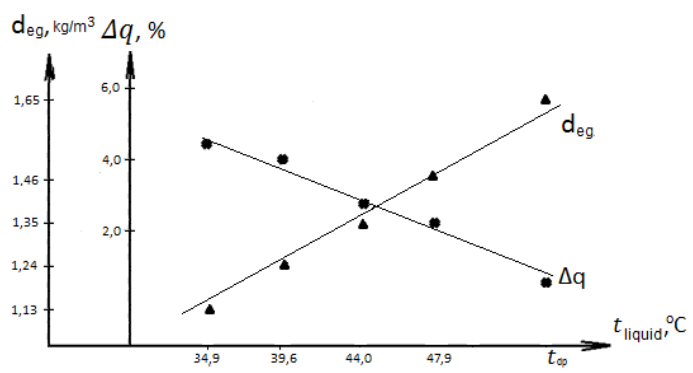

Fig. 5. Dependence of the moisture content of the flue gas $\mathrm{d}_{\mathrm{eg}}$ and $\ddot{\mathrm{q}} \mathrm{f}$ from water temperature on an entrance to a boiler
$M_{\mathrm{H}_{2} \mathrm{O}}^{e g} ; M_{\mathrm{H}_{2} \mathrm{O}}^{o}-$ content of water vapor in the flue gases leaving the combustion products and starting, respectively, in $\mathrm{kg}$ per $\mathrm{m}^{3}$ of combusted gas, $\mathrm{kg} / \mathrm{m}^{3}$;

$\tau$ - experience time, s;

- condensate flow during the experiment kg;

$B$ - gas consumption, $\mathrm{m}^{3} / \mathrm{s}$.

Then remaining in the flue gases of a rational amount of water vapor in their density

$\rho_{\mathrm{H}_{2} \mathrm{O}}=0,804 \mathrm{~kg} / \mathrm{m}^{3}$ is:

$V_{\mathrm{H}_{2} \mathrm{O}}^{e g}=\frac{M_{\mathrm{H}_{2} \mathrm{O}}^{e g}}{\rho_{\mathrm{H}_{2} \mathrm{O}}}=1,244 M_{\mathrm{H}_{2} \mathrm{O}}^{e g}, \mathrm{~m}^{3} / \mathrm{m}^{3}$ and the total

volume of the combustion products at the output parameters will be: $V_{f g}^{e g}=V_{d g}+V_{H_{2} \mathrm{O}}^{e g}, \mathrm{~m}^{3} / \mathrm{m}^{3}$.

The total volume of dry combustion products will be determined by (Kuznetsov, 1973):

$V_{d g}=V_{R O_{2}}+V_{N_{2}}^{o}+\left(\alpha_{d g}-1\right) V_{a}^{o}$

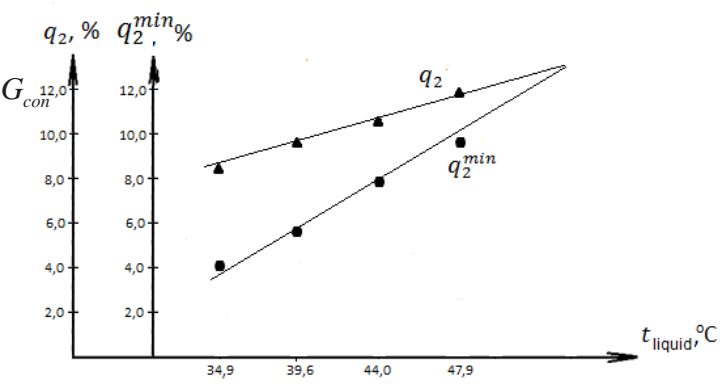

Fig. 4. Dependence of $q_{2}$, and $q_{2}^{\text {min }}$ from water temperature on an entrance to a boiler

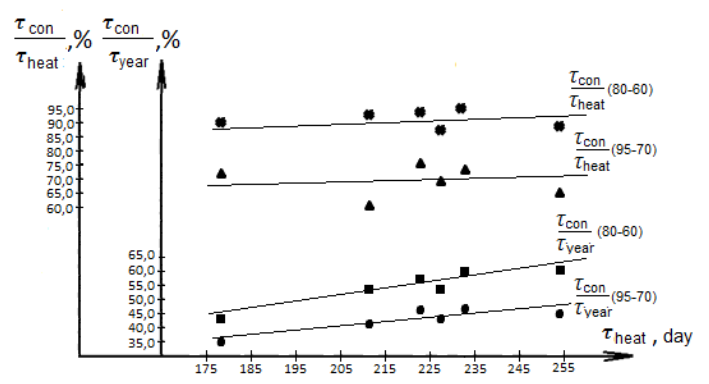

Fig. 6. Dependence of $\tau_{\text {con }} / \tau_{\text {heat }}$ è $\tau_{\text {con }} / \tau_{\text {year }}$ from the duration of the heating season 
For sulfur-free fuel gas:

$V_{\mathrm{RO}_{2}}=V_{\mathrm{CO}_{2}}=0,01\left(\mathrm{CO}+\mathrm{CH}_{4}+\sum m \cdot C_{m} \mathrm{H}_{n}+\mathrm{CO}_{2}\right)$, $\mathrm{m}^{3} / \mathrm{m}^{3}$;

$$
, \mathrm{m}^{3} / \mathrm{m}^{3}
$$

$V_{a}^{o}=0,0476\left(0,5 \mathrm{CO}+0,5 \mathrm{H}_{2}+1,5 \mathrm{H}_{2} \mathrm{~S}+\left(m+\frac{n}{4}\right) \mathrm{C}_{m} H_{n}-\mathrm{O}_{2}\right) \quad$, $\mathrm{m}^{3} / \mathrm{m}^{3}$.

Weight of dry gases can be expressed in terms of density:

$$
M_{d g}=\sum_{i=1}^{3} V_{i} \cdot \rho_{i}=V_{\mathrm{CO}_{2}} \cdot \rho_{\mathrm{CO}_{2}}+V_{N_{2}}^{o} \cdot \rho_{N_{2}}+\left(\alpha_{d g}-1\right) V_{a}^{o} \cdot \rho_{a}, \mathrm{~kg} / \mathrm{m}^{3}
$$

For the products of the combustion of gaseous fuels:

$V_{H_{2} \mathrm{O}}^{e g}=0,01 \cdot\left(H_{2}+H_{2} S+\sum \frac{n}{2} C_{m} H_{n}\right)+0,0161 \alpha_{d g} V_{a}^{o}, \mathrm{~m}^{3} / \mathrm{m}^{3} ;$

$d_{g}$ - moisture content of the fuel gas referred to 1 $\mathrm{m}^{3}$ of dry gas.

conditions:

Density of the gas under normal physical

$\rho_{\mathrm{CO}_{2}}=1,9768 \mathrm{~kg} / \mathrm{m}^{3}$;

$\mathrm{kg} / \mathrm{m}^{3}$;

$\rho_{a}=1,293 \mathrm{~kg} / \mathrm{m}^{3}$.

Accordingly, the mass of water vapor in the flue gases will be:

$M_{\mathrm{H}_{2} \mathrm{O}}^{o}=V_{\mathrm{H}_{2} \mathrm{O}} \cdot \rho_{\mathrm{H}_{2} \mathrm{O}}=0,804 V_{\mathrm{H}_{2} \mathrm{O}}, \mathrm{kg} / \mathrm{m}^{3}$.

Then the moisture content in the flue gases per $1 \mathrm{~kg}$ of the dry gas can be determined:

$d=\frac{M_{\mathrm{H}_{2} \mathrm{O}}^{e g} \cdot 1000}{M_{d g}}, \mathrm{~g} / \mathrm{kg}, M_{\mathrm{H}_{2} \mathrm{O}}^{e g}=M_{\mathrm{H}_{2} \mathrm{O}}^{o}-\Delta M_{\mathrm{H}_{2} \mathrm{O}}$, $\mathrm{g} / \mathrm{kg}$.

Reducing the moisture content in the flue gas is determined by the flow rate obtained in the experiment of condensate during the experiment:

$\Delta d=\frac{\Delta M_{\mathrm{H}_{2} \mathrm{O}}}{M_{d g}}=\frac{\frac{G_{c o n}}{B \cdot \tau}}{M_{d g}}, \mathrm{~g} / \mathrm{kg}, \Delta M_{\mathrm{H}_{2} \mathrm{O}}=M_{\mathrm{H}_{2} \mathrm{O}}^{o}-M_{\mathrm{H}_{2} \mathrm{O}}^{e g}, \mathrm{~g} / \mathrm{kg}$.

The resulting cumulative process, cooling and drying flue gas condensing boilers can be calculated from the flue gas temperature and combustion products chart id (Figure 1), if it is built for the combustion products, the gas used in the experiment.

\section{RESULTS}

\section{Different operating modes}

The tests were conducted for the gas fired condensing boiler with a two-spiral heat exchanger made of stainless steel with slotted channel and complete pre-mixing burner (London \& Case, 1962). The boiler of this series is intended for heating of family houses, town houses, as well as for the organization of the hot water system. The advantages of this boiler include ease of installation and operation, the model incorporated the ability to adapt the boiler to the type and quality

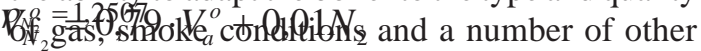
conditions. Prefabrication heat source for natural gas trunk, but if necessary, the boiler can be converted to run on LPG (Yudayev, 1981).

The greatest interest during tests was caused by a problem of determination of overall performance of condensation part of a boiler (tail part of the heat exchanger) at various temperatures of the heat carrier on an entrance to this surface, therefore, with various conditions of heat exchange

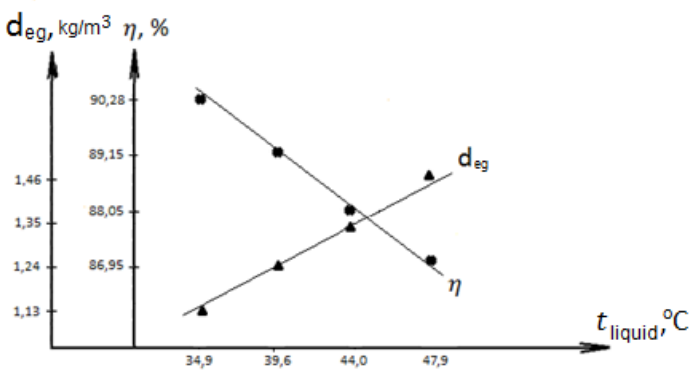

Fig. 8. Dependence of $d_{e g}$ and and the efficiency from water temperature on an entrance to a boiler rated temperature on heating
Fig. 7. Dependence of $\tau_{\text {con }} / \tau_{\text {heat }}$ è $\tau_{\text {con }}$ from

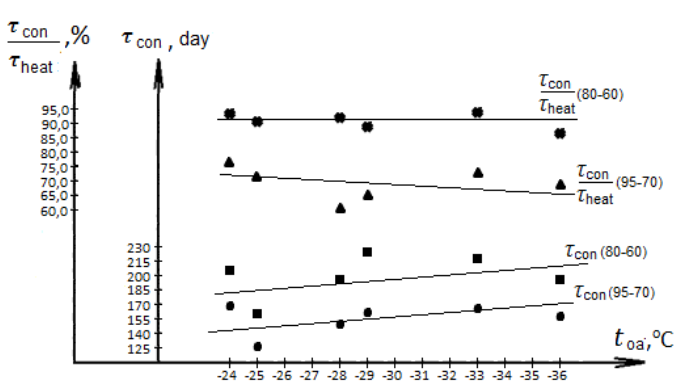




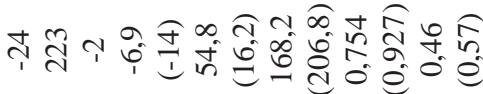

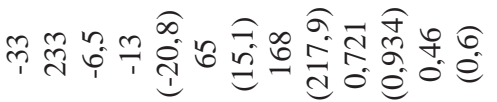

놋ำ

1

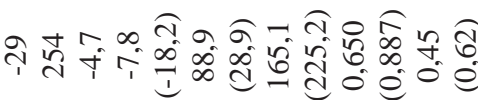

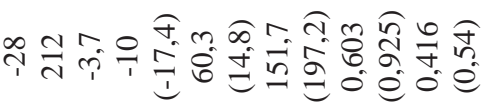

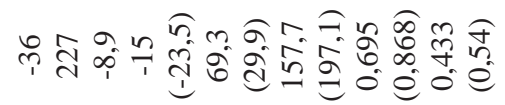

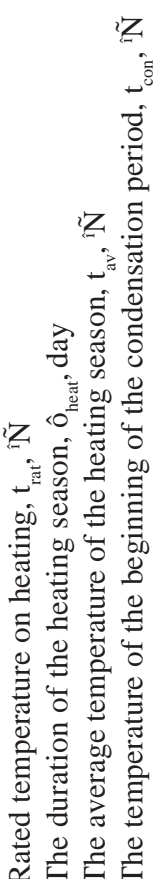

on a cold surface, i.e. with various share of condensation of water vapor from products of combustion as at traditional use for the analysis of overall performance of a boiler on the lower heating value on gaseous fuel only losses of heat from the exhaust gases $q_{2}$, loss of heat from the incomplete burning of chemical $q_{3}$ and loss from external cooling of $q_{5}$ are considered (Delyagin et al., 2010).

For this purpose, the test program has been drawn up with a variety of inlet water temperature in the heat exchanger of the boiler fire below the dew point of the flue gases. The fuel used natural gas of the following composition: $\mathrm{CH}_{4}=94,0 \% ; \mathrm{C}_{2} \mathrm{~N}_{6}=3,0 \% ; \mathrm{C}_{3} \mathrm{~N}_{8}=1,1 \% ; \mathrm{C}_{4} \mathrm{H}_{10}=$ $0,31 \% ; \mathrm{C}_{5} \mathrm{H}_{12}=0,36 \% ; \mathrm{H}_{2}=0,03 \% ; \mathrm{N}_{2}=1,3 \%$; $\mathrm{CO}_{2}=0,2 \%$; higher heating value: $Q_{H}^{V}=38390 \mathrm{~kJ} / \mathrm{m}^{3}$ (Ravich, 1971).

To determine the heat loss from the exhaust gases $Q_{2}$, empirically values were obtained flue gas temperature $t_{e q}$, fuel metering $B$ and fallen during condensation experiments. With these values id-diagram of the combustion products has determined the enthalpy of the flue gas $I_{e g}$.

The loss of heat from the exhaust gases are defined as the difference between the enthalpy of the combustion products at the output of the boiler unit and cold air (taken at $20^{\circ} \mathrm{C}$ ):

$Q_{2}=I_{e g}-\alpha_{d g} \cdot I_{a}, \mathrm{~kJ} / \mathrm{m}^{3} ;$

$\alpha_{d g}$ - coefficient of excess air;

$I_{a}$ - enthalpy of theoretically necessary amount of air, $\mathrm{kJ} / \mathrm{m}^{3}$.

In experiments determined the values of

flue gas temperature and enthalpy $t_{e g}$ flue gas $I_{e g}$ (figure 2, figure 3 ).

These values are calculated values $\mathrm{q}_{2}$, and boiler efficiency for different coolant temperatures $t_{\text {liquid }}$ :

The data obtained allow us to state the obvious dependence of the increase in efficiency of the boiler temperature decreases the water entering the boiler. It is also obvious that the test derived from the qualitative and quantitative assessments demonstrate dependence efficiency condensing boiler operating conditions from a fraction of condensed water vapor from the 
combustion products, i.e. the mode of operation of the water temperature at the inlet to the heat exchanger of the boiler.

In an explicit form noted dependence of change of losses of heat with the exhaust gases at the actual $\mathrm{q}_{2}$ and full cooling of combustion gases

$q_{2}^{\min }$ up to the heat carrier temperature on an entrance to a boiler is shown (figure 4).

For clarity, the figure shows the difference between these values (figure 5):

\section{Different climatic zones}

Use of heat of condensation of water vapor from products of combustion is especially favorable when burning fuel with the high content of hydrogen on the combustible weight and fuels with high content of moisture on working weight. So, when burning $1 \mathrm{~m}^{3}$ of natural gas $2 \mathrm{~m}^{3}$ of water vapor are formed (or $\sim 1,7 \mathrm{~kg}$ of water) that at full condensation of water vapor provides heat receipt to $11 \%$ of additional thermal energy. Efficiency of a condensation boiler considerably depends on completeness of use of this additional heat (Nesterenko, 1971). It will be carried out during the work with temperatures of surfaces of heating of a boiler lower than temperature of a dew-point of combustion gases on the low-temperature heat carrier, for example, according to the temperature schedule in system of heating of $60-40{ }^{\circ} \mathrm{C}$ that, however, significantly raises the price of system of heat supply in general, increasing capital investments more, than by $2-2,5$ times, taking into account boiler cost (Sosnin, 1974).

For climatic zones of Russia it is necessary to use temperature schedules with rather high settlement temperatures: $95-70^{\circ} \mathrm{C} ; 90$ $-70{ }^{\circ} \mathrm{C}$, at least $80-60^{\circ} \mathrm{C}$.

However, the called settlement temperatures for systems of heating and ventilation at high-quality regulation of output of heat assume existence of the long periods of operation of heat generators on lower adjustable temperatures of the heat carrier allowing the condensation mode (Bolgarsky, 1975). Duration of such periods will depend on climatic conditions in this district and, in particular, on number of hours of standing of low temperatures, duration and average temperature of the heating period, etc.

In this publication some selective results of an assessment of operating time of boilers are given in the condensation mode by creation of temperature schedules of work of $95-70^{\circ} \mathrm{C}$ and 80 $-60{ }^{\circ} \mathrm{C}$ for Moscow, St. Petersburg, Volgograd, Nizhni Tagil, Omsk, Arkhangelsk, according to duration of standing of temperatures. Boiler operating time in the condensation mode conditionally was considered for time during the heating period, when temperature of the return water in heating system $\mathrm{d}^{`} 50{ }^{\circ} \mathrm{C}$ (figure 6 , figure 7).

The selective characteristics provided in table 1 and in figures 6, 7 characterize only possible period of operation of boilers in the condensation mode (Sokolov, 2008), reflect influence of climatic factors on overall performance of a condensation boilers and are necessary material for their account in the analysis of size of efficiency of a boilers in an annual cycle of its work

Certain difficulties in such assessment of efficiency in time, are connected with a variable thermal operating mode of a boiler and dependence of efficiency on the water temperature on an entrance to a boiler (Mikheev \& Mikheeva, 1977).

The assessment of reliability of the obtained data was made by calculation of change of moisture content in combustion products $\mathrm{Äd}$ which was determined by the condensate consumption received for experience time.

Results of tests, on the example of condensation heat generators Baxi Duo-Tec Compact, De Dietrich Innovers PRO MCA 45 are given in figure 8 and reflect significant growth in efficiency of a condensation boiler at decrease in temperatures of the arriving water. At decrease in water temperature with $50^{\circ} \mathrm{C}$ to $35^{\circ} \mathrm{C}$ the efficiency on the higher heat value increases from $87 \%$ to $90 \%$ that corresponds to reduction of moisture content of combustion gases by $1 \mathrm{~m}^{3}$ of the burned natural gas from values $\mathrm{d}_{\mathrm{eg}}=1,7 \mathrm{~kg} / \mathrm{m}^{3}$ âî $\mathrm{d}_{\mathrm{eg}}=1,13$ $\mathrm{kg} / \mathrm{m}^{3}$ (figure 8 ).

\section{CONCLUSION}

Thus, the proposed method of studying the work of condensing boilers allows to detail the components of the heat balance of the boiler. To determine not only the efficiency, but also to evaluate the proportion of the heat of condensation of water vapor from the combustion products towards possible in any mode of operation. 
This study shows that the evaluation of the efficiency of the condensing boiler should be carried out taking into account the climatic zone, i.e., especially the heating period, the duration of standing relatively high temperatures, the possibility of using low-temperature heating schedules (50-30; 60-40) and the specific conditions of the boiler, for example, two-circuit condensing boilers when working on the hot water system with a temperature of the water supplied to the hot water supply more than $45^{\circ} \mathrm{C}$ condensing mode is not available.

Using selective climatic data and test results it can be argued that in the operational mode efficiency gas condensing boiler can be taken equal to $88-90 \%$ of the higher calorific value of the fuel, which is $8-11 \%$ higher than the operating efficiency of traditional boilers.

\section{REFERENCES}

1. Aronov I.Z. (1964). Contact gas economizers. Kiev. Technic.

2. Bolgarsky A.V. (1975). Thermodynamic and heat transfer. Ed. 2. Moscow. Higher school.

3. Bruykhanov O.N., Shevchenko S.N. (2014). Heat and Mass Transfer. Textbook. İoscow. Infra-M.

4. Delyagin G. N., Lebedev V. I., Permyakov B.A., Havanov P. A. (2010). Heat-generating installation. Studies for higher education institutions. 2nd ed. Moscow. Open company "Bastet's" IDES".

5. Isachenko V.P., Osipova V.A., Sukomel A.S. (1975). Heat transfer. Textbook for high schools, third edition. Moscow. Energiya.
6. Kalchevsky S. (2012). Renewable energy sources, waste energy in industry. Sofia. Avangard Prima.

7. Khavanov P.A. (2014). Sources of heat autonomous heating systems: monography. Moscow. MGSU.

8. Kuznetsov N.V. (1973). Thermal design of boiler units. Standard method. Moscow. Energiya.

9. London A.L., Case V.M. (1962). Compact Heat Exchangers. Moscow. Energiya.

10. Lukankin V.N., Shatrov M.G., Kamfer G.M. (2006). Heat: Textbook for universities. 5th edition. Moscow. High School.

11. Mikheev M.A., Mikheeva I.M. (1977). Fundamentals of heat transfer. Moscow. Energiya.

12. Miram A.O., Pavlenko V.A. (2011). Technical thermodynamics. Heatmass exchange: Educational edition. - Moscow. ASV.

13. Nesterenko A.V. (1971). Fundamentals of thermodynamic calculations of ventilation and air conditioning. Moscow. High School.

14. Petukhov B.S., Shickov V.K. (1987). Guide to the heat exchanger. Volume 1. Moscow. Energoatomizdat.

15. Ravich M. B. (1971). Fuel and efficiency of its use. Moscow. Science.

16. Roddatis K.F., Poltaretsky A.N. (1989). Guide to the boiler plants with low productivity. Moscow. Energoatomizdat.

17. Sokolov B. A. (2008). Boiler installation and exploitation. Moscow. Publisher Academy

18. Sosnin Y.P. (1974). Water heaters. Moscow. Stroyizdat.

19. Trembovlya V. I. (1977). K.U. heattechnical tests. Moscow. Energy.

20. Yudayev B. N. (1981). Heat transfer. The textbook for higher education institutions. 2nd ed. Moscow. Graduate School. 